\title{
IMPACT OF ENVIRONMENTAL CONDITIONS ON PHOTOSYNTHESIS, GROWTH AND CARBON ALLOCATION STRATEGIES OF HYPERSALINE SPECIES OF DUNALIELLA
}

\author{
M. GIORDANO ${ }^{1, *}$ \\ J. BEARDALL ${ }^{2}$
}

\author{
${ }^{1}$ Dipartimento di Scienze del Mare \\ Università Politecnica delle Marche \\ Via Brecce Bianche, 60131 Ancona, Italy \\ ${ }^{2}$ School of Biological Sciences, Monash University, \\ Clayton, VIC 3800, Australia
}

Received: 19/08/08

Accepted: 20/10/08

\begin{abstract}
Hypersaline environments pose a number of ecological and metabolic challenges to the organisms that live in them. Primary producers, such as halotolerant species of the green microalgal genus Dunaliella, are no exception. In this paper we focus on the problems posed to the acquisition and metabolism of inorganic nutrients and on the consequences of exposure to high light and UV radiation. We show that not only does growth in high salinity environments have repercussions on the flow of carbon into osmolytes such as glycerol, it also affects speciation of inorganic carbon and the uptake of inorganic ions by the cells. The strategies that Dunaliella adopt to optimize resource utilization and the interactions among metabolic pathways are also discussed.
\end{abstract}

KEYWORDS: Dunaliella; photosynthesis; allocation strategies; inorganic carbon acquisition, nutrients, light, UVR.

\section{INTRODUCTION}

Chlorophyte algae of the genus Dunaliella are found in nature in many salt-water habitats. In most marine environments the genus never comprises a major component of algal populations. In hypersaline environments however, species such as $D$. salina, D. parva and $D$. viridis are found as the dominant microalgae in the water column. Examples of Dunaliella as the major microalga in natural populations are found from the Dead Sea, Israel (Nissenbaum, 1975), the Pink Lake in Australia (Borowitzka, 1981), and the Great Salt Lake in the USA (Post, 1981 ). D. parva and D. salina are the dominant spring phytoplankton species in the athalassic lake of Fuenta de Piedra in Spain (Jimenez et al., 1990).

The taxonomy of Dunaliella species has, in the past, been disputed (Masyuk, 1973; Ginzburg, 1987; Preisig, 1992). Three major genera of Dunaliella capable of growth at high salinities are now generally accepted. $D$. salina appears red when cultured at high salinities, $D$. parva appears yellowish and has a lower carotenoid content, whereas $D$. viridis remains green even at elevated salinity. D. tertiolecta is mesohaline and stays green even at salinities above its optimum for growth (Borowitzka and Borowitzka, 1988). Because of their ability to grow and thrive at high salinities, Dunaliella species are the predominant algae in saltworks and naturally occurring hypersaline environments. Dunaliella salina for instance grows over a range of salinities from $\sim 0.033 \mathrm{M}$ to saturated salt solutions $(5.8 \mathrm{M})$, with an optimum around $2 \mathrm{M} \mathrm{NaCl}$ (Ben Amotz and Avron, 1989). D. viridis can grow in up to $5 \mathrm{M} \mathrm{NaCl}$ with a broad optimum around 1.0 to $2 \mathrm{M} \mathrm{NaCl}$ (Borowitzka and Borowitzka, 1988; Jiménez and Niell, 1991), though the optimal salinity for $D$. viridis growth is dependent on temperature (Jiménez and Niell, 1991). In contrast, the mesohaline $D$. tertiolecta is only capable of growth up to 1.67 M. Isolates from hypersaline lakes in the Vestfold Hills, Australian Antarctic Territory showed 
little effect of salinity on growth over the range 0.2 to $1.7 \mathrm{M}(\mathrm{Xu}, 1994)$. A more detailed description of the ecology of Dunaliella species is to be found in Borowitzka and Borowitzka (1988).

In addition to variations in salinity, Dunalella spp. in saltworks are exposed to high levels of light, as both photosynthetically active radiation (PAR 400-700nm) and UV radiation (280-320 and $320-400 \mathrm{~nm}$, for the UVB and UVA ranges respectively) as well as variations in temperature and nutrients. The following paragraphs will deal with the effects of these environmental factors on the biology of Dunaliella spp.

\section{LIGHT AND UV}

Maximal growth rates of $D$. euchlora and $D$. salina have been reported as occurring at $>180$ $\mu \mathrm{mol} \mathrm{m} \mathrm{m}^{-2}$ and $127 \mu \mathrm{mol} \mathrm{m} \mathrm{m}^{-2} \mathrm{~s}^{-1}$ respectively (Chang et al., 1986), though these authors note a complex interaction between light, salinity and temperature in determining growth rates, with light being less important than the other two environmental parameters. In $D$. tertiolecta, growth saturates at $\sim 150 \mu \mathrm{mol} \mathrm{m}^{-2} \mathrm{~s}^{-1}$, and photoinhibition is not observed below $300 \mu \mathrm{mol} \mathrm{m}^{-2} \mathrm{~s}^{-1}$ (Quigg and Beardall, 2003).

Photosynthesis saturates at somewhat higher photon fluxes, with $D$. parva showing saturation at $\sim 400-600 \mu \mathrm{mol} \mathrm{m}{ }^{-2} \mathrm{~s}^{-1}$ depending on salinity (Jiménez et al., 1990) and D. tertiolecta photosynthesis saturating at $100-200 \mu \mathrm{mol} \mathrm{m}^{-2} \mathrm{~s}^{-1}$, depending on growth rate (e.g. Young and Beardall, 2005).

Although growth on high concentrations of $\mathrm{NH}_{4}{ }^{+}$rather than $\mathrm{NO}_{3}{ }^{-}$as the sole $\mathrm{N}$ source leads to a stimulation of both maximal rates of photosynthesis $\left(P_{\max }\right)$ and apparent quantum yield, in $D$. salina, this has no obvious repercussions for the photon flux density required to saturate photosynthesis or on the light compensation point, nor does it impact on the susceptibility of cells to photoinhibition (Giordano and Bowes, 1997).

There is little information on the UV sensitivity of $D$. salina and other hypersaline tolerant Dunaliella species. Hermann et al. (1997) studied the effects of UV on D. salina, and reported that the inhibitory effects of the different wavelengths of solar radiation increased as UVB $>U V A>P A R$ with the relative mean effectiveness of these classes being $\sim 2 \times 10^{-4}\left(\mu \mathrm{mol} \mathrm{m}{ }^{-}\right.$ $\left.{ }^{2} \mathrm{~s}^{-1}\right)^{-1}$ for UVB, $4 \times 10^{-6}\left(\mu \mathrm{mol} \mathrm{m} \mathrm{m}^{-2} \mathrm{~s}^{-1}\right)^{-1}$ for UVA and $2 \times 10^{-7}\left(\mu \mathrm{mol} \mathrm{m} \mathrm{m}^{-2} \mathrm{~s}^{-1}\right)^{-1}$ for PAR. Curiously, White and Jahnke (2002) report that whereas up to $24 \mathrm{~h}$ exposure to UVB had no effect on photosynthetic quantum yield of both $D$. salina and $D$. bardawil, UVA strongly decreased quantum efficiency, particularly in $D$. bardawil and in $D$. salina grown at low light. Beardall et al. (2002) have shown that quantum yield of photosynthesis in D. tertiolecta is inhibited by $\sim 50 \%$ by $60 \mathrm{~min}$ exposure to $2.8 \mathrm{~W} \mathrm{~m}^{-2}$ UVB. Inhibitory effects of UVB to photosynthesis of $D$. tertiolecta are enhanced by $\mathrm{N}$-limitation (Shelly et al., 2002) and Pstarvation (Shelly et al., 2005; Heraud et al., 2005).

Light also plays a crucial role in one of the feature that makes Dunaliella a very important organism for biotechnology: carotenogenesis. The biosynthesis of $\beta$-carotene appears to be unrelated to light quality within the PAR region, but it is rather dependent on the overall amount of light received by the organism over one cell division (Ben-Amotz and Avron, 1989; Ben-Amotz and Shaish, 1992 and references therein). This may, to some extent, be related to the fact that, in carotenogenic Dunaliella, most $\beta$-carotene is located at the periphery of the chloroplasts and is not associated with the photosynthetic antenna (Borowitzka and Borowitzka, 1988). However, the isomeric composition of the $\beta$-carotene pool may not be totally unrelated to the wavelength composition of the incident radiation, since the trans to cis transition leads to a shift in the absorption maxima and the appearance of a peak in the UV region (Ben-Amotz and Shaish, 1992 and references therein).

\section{NUTRIENTS}

The range of environments that Dunaliella salina inhabits is characterized by large variations in nutrient availability. The impact of $D$. salina in saltworks, even in crystallizer basins, is highest when poor management of biological processes induces an increase of nutrients (Davis, 2000; Delapsakis et al., 2005) and this can lead to substantial physiological changes 
in D. salina cells (Giordano et al., 1994; Giordano and Bowes, 1997). Nitrate concentration in the range 0.5 to $10 \mathrm{mM}$ had little effect on growth rates of $D$. viridis (Jiménez and Niell, 1991). Although some authors reported that high concentrations of ammonium (>2.5 M) were lethal for Dunaliella species (Grant, 1968), D. salina (Giordano et al., 1994) and D. parva (Giordano et al., 2002) are capable of adaptation to growth on $\mathrm{N}$ concentrations up to 10 and $5 \mathrm{mM}$, respectively, regardless of whether the $\mathrm{N}$ source is $\mathrm{NH}_{4}{ }^{+}$or $\mathrm{NO}_{3}{ }^{-}$. Cells acclimated to growth on high $\mathrm{NH}_{4}{ }^{+}$concentrations usually showed similar division rates and larger cell size than their high $\left[\mathrm{NO}_{3}{ }^{-}\right.$-grown counterparts (Giordano and Bowes, 1997).

The storage capacity for $\mathrm{NO}_{3}{ }^{-}$seems to be relatively small (1 order of magnitude lower than in diatoms; Lomas and Gilbert, 2000). However, Del Rio et al. (1993) provided some evidence that nitrate reduction could be conducted even in the dark, thanks to the allegedly rather unusual (see Giordano et al., 2005 and references therein) properties of $D$. salina nitrate reductase. The ability to take up and assimilate $\mathrm{NO}_{3}{ }^{-}$even at night could make a big difference in terms of the strategy for $\mathrm{N}$ utilization in this microalga; further studies are however needed to clarify this controversial aspect of $\mathrm{NO}_{3}{ }^{-}$reduction in $D$. salina. The ability to actively take up and store $\mathrm{N}$ as $\mathrm{NH}_{4}{ }^{+}$is also still rather controversial (Pick et al., 1991; Lomas and Gilbert, 2000, Giordano and Bowes, 1997; Giordano et al., 2000). The presence of either form of inorganic $\mathrm{N}$, especially at high concentrations, plays a major role in the photosynthetic performances of $D$. salina and on the pattern of resource allocation (see below) (Giordano et al., 1994; 2002; Giordano and Bowes, 1997; Giordano, 2001; Norici et al., 2002).

Of the other major nutrients, optimal concentrations of $P$ for $D$. salina are 0.15 to $0.18 \mathrm{mM}$, with growth being inhibited above $36 \mathrm{mM}$ (Borowitzka and Borowitzka, 1988), whereas sulfate saturates $D$. salina growth at around $0.30 \mathrm{mM}$ (Giordano et al., 2000).

To the best of our knowledge, no data are available on the kinetics of inorganic nitrogen uptake for hypersaline species. However, the ability of Dunaliella to take up nitrate, at least for the marine species $D$. tertiolecta, is characterized by a relatively low affinity for the substrate (Ks about $11 \mu \mathrm{M}, \sim 5-30$ times higher than that found for diatoms) and similar to that of some dinoflagellates (but $\sim 0.5$ times that in other dinoflagellate species), and a relatively small capacity (Lomas and Gilbert, 2000). Maximal uptake rates are reported as $18 \mathrm{fmol} \mathrm{N} \mathrm{h}^{-1} \mathrm{cell}^{-1}$ (0.005 fmol $\mathrm{N} \mathrm{h}^{-1} \mathrm{fmol}^{-1} \mathrm{C}$ ) (Lomas and Gilbert, 2000).

Half saturation for $P$ uptake by $D$. tertiolecta is $\sim 1 \mu \mathrm{M}$ but maximal uptake rates vary from 14 to $26 \mathrm{ng} \mathrm{P}\left(10^{6} \text { cells }\right)^{-1} \mathrm{~min}^{-1}$ depending on the growth rate (Roberts et al., 2008).

Limitation of growth by diminished supply of N, P, S and Fe all have effects on the ability of Dunaliella species to acquire carbon and allocation of $C$ to cellular components. This is dealt with in more detail below.

Growth of $D$. salina on high concentrations of $\mathrm{NH}_{4}{ }^{+}$leads to nearly a doubling of the chlorophyll per cell, when compared to growth on equal concentrations of $\mathrm{NO}_{3}{ }^{-}$(Giordano and Bowes, 1997). The effect of the $\mathrm{N}$-source on cellular $\beta$-carotene content is much smaller, albeit noticeable $\left(30-50 \%\right.$ increase under $\left.\mathrm{NH}_{4}{ }^{+}\right)$, with a consequent increase in the chlorophyll to $\beta$-carotene ratio (Giordano and Bowes, 1997). The algae cultured on $\mathrm{NH}_{4}{ }^{+}$rather than on $\mathrm{NO}_{3}{ }^{-}$increased not only the amount of chlorophyll per cell $(\sim 70 \%)$ but also the apparent chlorophyll concentration $(\sim 50 \%)$, despite the $\mathrm{NH}_{4}{ }^{+}$-related increase in cell size $(\sim 20 \%)$. The magnitude of the effect of the $\mathrm{N}$-source on the cell content $(\sim 50 \%)$ and apparent concentration $(\sim 10 \%)$ of $\beta$-carotene was smaller, but this did not substantially affect the chlorophyll to $\beta$-carotene ratio (Giordano and Bowes, 1997). The amount of $\mathrm{N}$ available also plays an important role in the production of $\beta$-carotene. In combination with temperature, salinity and light, $\mathrm{N}$-limitation is among the most potent inducers of carotenogenesis in the carotenogenic strains of Dunaliella (e.g. Ben-Amotz and Shaish, 1992). In general, factors causing a decline in the growth rate (primarily nutrient limitation) lead to the accumulation of $\beta$-carotene in Dunaliella cells (e.g. Ben-Amotz and Shaish, 1992).

The concentration of $\mathrm{CO}_{2}$ for growth affects chlorophyll concentration in $D$. salina only indirectly, via a change in cell volume. When $D$. salina is cultured at ambient $\mathrm{CO}_{2}$ or at $5 \%$ $\mathrm{CO}_{2}$, no significant variation in the chlorophyll cell content can be observed, though the 
increased volume of high- $\mathrm{CO}_{2}$ grown cells dilutes the chlorophyll concentration by a factor of two (Giordano and Bowes, 1997). It should however be noted that it was not demonstrated that the change in whole cell volume corresponded to equal changes of chloroplast size.

\section{INORGANIC CARBON ACQUISITION}

Among the consequences of a high salinity environment are a decrease in $\mathrm{CO}_{2}$ solubility and a shift in the equilibrium between $\mathrm{CO}_{2}$ and $\mathrm{HCO}_{3}{ }^{-}$. Dunaliella salina responds to this decrease in $\mathrm{CO}_{2}$ and increase in $\mathrm{HCO}_{3}{ }^{-}$at higher salinity by increasing the activity of a $\mathrm{CO}_{2}$ concentrating mechanism (CCM) (Zenvirth and Kaplan, 1981; Booth and Beardall, 1991), though even at lower salinities, the CCM is as active as in the mesohaline D. tertiolecta (Zenvirth and Kaplan, 1981; Young et al., 2001). Enhanced activity of the CCM of $D$. salina at high salinity is accompanied by elevated levels of an external carbonic anhydrase ( $\left.\mathrm{CA}_{\text {ext }}\right)$ (Booth and Beardall, 1991). D. salina adapted to high salinity shows induction of an unusual external $\alpha$-type CA that retains its activity over the range of salinities from $0-4 \mathrm{M} \mathrm{NaCl}$ (Fisher et al., 1996; Premkumar et al., 2006). This $\mathrm{CA}_{\text {ext }}$ consists of two internally duplicated tandem repeated sequences fused into a single polypeptide of $60 \mathrm{kDa}$. This may be compared to the periplasmic CAs from the freshwater Chlorophyte, Chlamydomonas, that consist of $75 \mathrm{kDa}$ heterotetramers of 2 large and 2 small subunits and which are $90 \%$ inhibited by $0.6 \mathrm{M} \mathrm{NaCl}$ (Premkumar et al., 2006).

$D$. salina cells adapted for several generations to growth on high $\mathrm{NH}_{4}{ }^{+}$concentrations (Giordano et al., 1994) are more effective at utilizing light and $\mathrm{CO}_{2}$, than those grown on $\mathrm{NO}_{3}{ }^{-}$, with $\mathrm{NH}_{4}{ }^{+}$grown cells showing a halving of their photosynthetic $\mathrm{K}_{1 / 2}\left(\mathrm{CO}_{2}\right)$. This is indirect evidence of the fact that the chemical source of $\mathrm{N}$ modulates the effectiveness of $D$. salina $\mathrm{CO}_{2}$ concentrating mechanisms. The high $\mathrm{P}_{\max }$ and low $\mathrm{K}_{1 / 2}\left(\mathrm{CO}_{2}\right)$ of photosynthesis in $\mathrm{NH}_{4}{ }^{+}$ grown cells are associated with an increase of both Rubisco activity and Rubisco protein abundance and concentration. The increase of Rubisco protein under these growth conditions is not simply a result of a general increase of protein, since Rubisco abundance increases even relative to total protein (Giordano and Bowes, 1997). Periplasmic CA activity, which may also play an important role in facilitating $\mathrm{CO}_{2}$ acquisition (e.g. Giordano et al., 2005), also increases when $\mathrm{N}$ was available as $\mathrm{NH}_{4}{ }^{+}$rather than as $\mathrm{NO}_{3}{ }^{-}$. This increase in activity is substantially larger than the cell volume increase under the same conditions; however, its relevance with respect to the photosynthetic response remains somewhat obscure, since the actual rates of CA-catalyzed dehydration of $\mathrm{HCO}_{3}{ }^{-}$to $\mathrm{CO}_{2}$ are far above the photosynthetic requirements, even for $\mathrm{NO}_{3}^{-}$-grown cells (Giordano and Bowes, 1997).

In $D$. salina, the induction of a CCM subsequent to the transfer from $5 \% \mathrm{CO}_{2}$ to atmospheric $\mathrm{CO}_{2}$ is associated with a decline of Rubisco abundance per cell by as much as $50 \%$. However, low- $\mathrm{CO}_{2}$-grown cells are much smaller (40 to $45 \%$ ) than their high $\mathrm{CO}_{2}$ counterparts; consequently, apparent Rubisco protein concentration is not compromised by the transfer to low $\mathrm{CO}_{2}$. The concomitance between cell volume reduction and Rubisco downregulation makes it difficult to understand whether the latter is part of the CCM induction process or is due to the change in cell size.

In contrast to the effects of $\mathrm{N}$ source on acquisition of inorganic carbon, in $D$. tertioleta at least, N-limitation leads to diminished Rubisco levels but enhanced CCM activity, leading to improved $\mathrm{N}$-use efficiency of $\mathrm{C}$ assimilation under low $\mathrm{N}$ (Beardall et al., 1991; Young and Beardall 2005). Although Fe-limitation of $D$. tertiolecta showed similar consequences to those of $\mathrm{N}$-limitation (Young and Beardall, 2005), P-limitation of $D$. tertiolecta leads to a decreased CCM activity, presumably due to a lower availability of ATP to drive active transport processes (Beardall et al., 2005).

\section{THE FATE OF ASSIMILATED CARBON}

It is interesting that $D$. salina is genotypically equipped to deal with high $\mathrm{N}$ concentration and is able not only to increase the activity of enzymes related to $\mathrm{N}$-assimilation and $\mathrm{C}$-skeleton construction, but also to induce specific isoforms of relevant enzymes when needed (Giordano et al., 2002; Norici et al., 2002). It is especially worthy of note, for instance, that a specific isoform of PEPc, different from those present at relatively low concentrations of both 
$\mathrm{NO}_{3}{ }^{-}$and $\mathrm{NH}_{4}{ }^{+}$, is expressed when cells are exposed to high concentrations of $\mathrm{NH}_{4}{ }^{+}$(Norici et al., 2002). The importance of this anaplerotic enzyme (Norici and Giordano, 2002) in the detoxification of the cellular environment by excess $\mathrm{NH}_{4}{ }^{+}$is consistent with the overall physiological patterns of high $\mathrm{NH}_{4}{ }^{+}$grown cells (Giordano and Bowes, 1997). PEPC is not only up-regulated in cells acclimated to growth in $\mathrm{NH}_{4}{ }^{+}$, but it also appears pivotal in the short term (minutes to hours) and medium term (hours to few days; = from one to a few generations) responses to changes in N-source (Giordano et al., 2007). This activity is in fact among the few physiological parameters that do not respond homeostatically (sensu Montechiaro et al., 2006) to a transition from $\mathrm{NO}_{3}{ }^{-}$to $\mathrm{NH}_{4}{ }^{+}$, but is present at a higher level in the presence of incremental amounts of $\mathrm{NH}_{4}{ }^{+}$, compared to when $\mathrm{NO}_{3}{ }^{-}$is the sole $\mathrm{N}$-source. Differences between cells acclimated/adapted to high $\mathrm{NH}_{4}{ }^{+}$(Giordano and Bowes, 1997) and cells subjected to a gradual change of $\mathrm{N}$-source from $\mathrm{NO}_{3}{ }^{-}$to $\mathrm{NH}_{4}{ }^{+}$(Giordano et al., 2006) are however obvious: while the carbon allocation in cells acclimated to high $\mathrm{NH}_{4}{ }^{+}$undergoes substantial rearrangements with a large amount of $C$ being invested in protein synthesis (Giordano and Bowes, 1997), the gradual transition causes only a transitory disturbance (within hours from change of $\mathrm{N}$-source) in the ratio between protein and carbohydrates, which is brought back to the same relative proportions as had existed before the supply of $\mathrm{NH}_{4}{ }^{+}$. This occurs within about a day or two. This difference may have crucial repercussions for salt production in salt works. The quality of salt is negatively affected by the presence of organic matter in the crystallizer ponds. The amount of organic matter, possibly amino acids, released by $D$. salina can be substantial when cells are acclimated/adapted to high $\mathrm{NH}_{4}{ }^{+}$ concentrations (Giordano et al., 1994); the maintenance of a balance between protein and carbohydrates during a medium term transition is instead suggestive of a rather moderate release of organic carbon, even if the peak in protein abundance that occurs soon after the change of $\mathrm{N}$ source could lead to a brief episode of organic release. This thus calls for careful management of the biological processes in saltworks to avoid excess production of $\mathrm{NH}_{4}{ }^{+}$, especially for a prolonged period of time.

In conditions of severe nutrient limitation, $D$. salina can undergo dramatic alterations to metabolism and composition to ensure maintenance of essential functions. In high salinity basins, glycerol production is paramount. It has been observed that a reduced supply of an essential nutrient like sulfur strongly affects the utilization of other nutrients, in particular $\mathrm{C}$ and N (Giordano et al., 2000). The reduction of $C$ assimilation causes a shortage of organic carbon in the cells. The inhibition of $\mathrm{N}$ assimilation on the other hand causes an imbalance in the $\mathrm{C}$ to $\mathrm{N}$ ratio. Under this circumstance, $\mathrm{C}$ is diverted from 4 and $5 \mathrm{C}$ compounds, possibly to ensure that sufficient C-skeletons are available for glycerol metabolism (Giordano et al., 2000). Similar studies have not been conducted under limitation by other nutrients, but it can be expected that similar metabolic patterns are induced whenever, in $D$. salina, glycerol content per cell decreases when $\mathrm{N}$ is made available as $\mathrm{NH}_{4}{ }^{+}$and when $\mathrm{CO}_{2}$, concentration is high (5\%) (Giordano and Bowes, 1997). Under these growth regimes, glycerol concentrations appear to be insufficient to provide the osmolarity needed to compensate for that in the external medium (Giordano and Bowes, 1997). An alternative osmolyte must therefore fill in for the shortage of glycerol.

\section{CONCLUSIONS}

In spite of the large amount of published information on the hyperhaline species of Dunaliella (e.g. Borowitzka and Borowitzka, 1988; Avron and Ben-Amotz, 1992), substantial gaps exist in the understanding of the biochemical and molecular mechanisms governing the ecophysiology of this organism. For instance, more studies are required before a satisfactory comprehension of the kinetics of nutrient uptake and of the strategies for the allocation of resources is attained. This information would help to decipher the ecological role of Dunaliella in hyperhaline ecosystems, especially in terms of its contribution to trophic chains and water quality. In particular, salt production in saltworks would greatly benefit from a more thorough understanding of the factors that control Dunaliella growth and modulate the release of organic matter from its cells. Due to the biotechnological relevance of this organism, it is possible that important information has not been made available to the scientific community for commercial reasons. 


\section{REFERENCES}

- Avron M. and Ben-Amotz A. (1992), Dunaliella: Physiology, Biochemistry and Biotechnology", CRC, Boca Raton.

- Beardall J, Roberts S. and Millhouse J. (1991), Effects of nitrogen limitation on inorganic carbon uptake and specific activity of ribulose-1,5- $\mathrm{P}_{2}$ carboxylase in green microalgae, Canadian Journal of Botany, 69, 1146-1150.

- Beardall J., Roberts S. and Raven J.A. (2005), Regulation of inorganic carbon acquisition by phosphorus limitation in the green alga Chlorella emersonii, Canadian Journal of Botany, 83, 859-864.

- Ben-Amotz A. and Avron M. (1989), The wavelength dependence on massive carotene significance in Dunaliella bardawil (Chlorophyceae). Journal of Phycology, 25, 175-178.

- Ben-Amotz A. and Shaish A. (1992), $\beta$-carotene biosynthesis. In: Dunaliella: Physiology, Biochemistry and Biotechnology, M. Avron and A. Ben-Amotz (Eds.), CRC, Boca Raton, pp. 205-216.

- Booth W.A. and Beardall J. (1991), Effects of salinity on inorganic carbon utilization and carbonic anhydrase activity in the halotolerant alga Dunaliella salina (Chlorophyta), Phycologia, 30, 220-225.

- Borowitzka M.A. and Borowitzka L.J. (1988), Dunaliella. In: Microalgal Biotechnology, MA Borowitzka and LJ Borowitzka (Eds.), Cambridge University Press, Cambridge, UK, pp. 27-58.

- Davis J.S. (2000), Structure, function, and management of the biological system for seasonal solar saltworks, Global NEST: The International Journal, 2, 217-226.

- Del Rio M.J., Ramazanov Z. and Garcia-Reina G. (1994), Dark induction of nitrate reductase in the halophilic alga Dunliella salina, Planta, 192, 40-45.

- Dolapsakis N.P., Tafas T., Abatzopoulos T.J., Ziller S. and Economou-Amilli A. (2005), Abundance and growth response of microalgae at Megalon Embolon solar saltworks in northern Greece: An aquaculture prospect, Journal of Applied Phycology, 17, 39-49.

- Ginzburg M. (1987), Dunaliella: a green alga adapted to salt, Advances in Botanical Research, 14, 93-183.

- Giordano M. (1997), Adaptation of Dunaliella salina (Volvocales, Chlorophyta) to growth on $\mathrm{NH}_{4}{ }^{+}$as the sole $\mathrm{N}$ source, Phycologia, 36, 345-350.

- Giordano M. and Bowes G. (1997), Gas exchanges, C-allocation, in Dunaliella salina cells in response to the $\mathrm{N}$ source and $\mathrm{CO}_{2}$ concentration used for growth, Plant Physiology, 115, 1049-1056.

- Giordano M., Chen Y., Koblizek M. and Falkowski P. (2005), Regulation of nitrate reductase in Chlamydomonas reinhardtii by the redox state of the PQ pool, European Journal of Phycology, 40, 345-352.

- Giordano M., Davis J.S. and Bowes G. (1994), Organic carbon release by Dunaliella salina (Chlorophyta) under different growth conditions of $\mathrm{CO}_{2}$, nitrogen, and salinity, Journal of Phycology, 30, 249-257.

- Giordano M., Norici A. and Gilmour D.J. (2002), Influence of the nitrogen source and metabolites on phosphoeno/pyruvate carboxylase activity in the unicellular green alga Dunaliella parva CCAP 19/9, Phycologia, 41, 133-137.

- Giordano M., Norici A., Gilmour D.J. and Raven J.A. (2007), Responses of the green alga Dunaliella parva (Volvocales, Chlorophyta) to controlled incremental changes in the N-source, Functional Plant Biology, 34, 1-10.

- Giordano M., Pezzoni V. and Hell R. (2000), Strategies for the allocation of resources under sulfur limitation in the green alga Dunaliella salina, Plant Physiology, 124, 857-864.

- Giordano M. (2001), Interactions between C and N metabolism in Dunaliella salina cells cultured at elevated $\mathrm{CO}_{2}$ and high $\mathrm{N}$ concentrations, Journal of Plant Physiology, 158, 577581. 
- Heraud P., Roberts S., Shelly K. and Beardall J. (2005), Interactions between UVB exposure and phosphorus nutrition: II. Effects on rates of damage and repair, Journal of Phycology, 41, 1212-1218.

- Hermann H., Häder D.-P. and Ghetti F. (1997), Inhibition of photosynthesis by solar radiation in Dunaliella salina: relative efficiencies of UV-B, UV-A and PAR, Plant Cell and Environment, 20, 359-365.

- Jiménez C. and Niell F.X. (1990), Influence of temperature and nitrogen concentration on photosynthesis of Dunaliella viridis Teodoresco, Journal of Applied Phycology, 2, 309-317.

- Jiménez C. and Niell F.X. (1991), Growth of Dunaliella viridis Teodoresco: effect of salinity, temperature and nitrogen concentration, Journal of Applied Phycology, 3, 319-327.

- Jiménez C., Niell F.X. and Fernández J.A. (1990), The photosynthesis of Dunaliella parva Lerche as a function of temperature, light and salinity, Hydrobiologia, 197, 165-172.

- Lomas M.W. and Gilbert P.M. (2000), Comparison of nitrate uptake, storage, and reduction in marine diatoms and flagellates, Journal of Phycology, 36, 903-913.

- Marin N., Morales F., Lodeiros C. and Tamigneaux E. (1998), Effect of nitrate concentration on growth and pigment synthesis of Dunaliella salina cultivated under low illumination and preadapted to different salinities, Journal of Applied Phycology, 10, 405-411.

- Masyuk N.P. (1973), Morphology, taxonomy, ecology and geographic distribution of the genus Dunaliella Teod. and prospects for its potential utilisation, Naukova Dumka, Kiev.

- Norici A. and Giordano M. (2002), Anaplerosis in microalgae, Recent Research Developments in Plant Physiology, 3, 153-164.

- Norici A., Dalsass A. and Giordano M. (2002), Role of phosphoenolpyruvate carboxylase in anaplerosis in the green microalga Dunaliella salina cultured under different nitrogen regimes, Physiologia Plantarum 116, 186-191.

- Preisig H.R. (1992), Morphology and taxonomy. In: Dunaliella: Physiology, Biochemistry and Biotechnology, M. Avron and A. Ben-Amotz (Eds.), CRC, Boca Raton, pp. 1-15.

- Quigg A. and Beardall J. (2003), Protein turnover in relation to maintenance metabolism at low photon flux in two marine microalgae, Plant Cell and Environment, 26, 693-703.

- Roberts S., Shelly S. and Beardall J. (2008) Interactions between phosphate uptake, photosynthesis and chlorophyll fluorescence in nutrient-limited cultures of the chlorophyte microalga Dunaliella tertiolecta, Journal of Phycology, 44, 662-669.

- Shelly K., Heraud P. and Beardall J. (2002), Nitrogen limitation in Dunaliella tertiolecta Butcher (Chlorophyceae) leads to increased susceptibility to damage by ultraviolet-B radiation but also increased repair capacity, Journal of Phycology, 38, 1-8.

- Shelly K., Roberts S., Heraud P. and Beardall J. (2005), Interactions between UVB exposure and phosphorus nutrition: I. Effects on growth, phosphate-uptake and chlorophyll fluorescence, Journal of Phycology, 41, 1204-1211.

- White A.L. and Jahnke L.S. (2002), Contrasting effects of UV-A and UV-B on photosynthesis and photoprotection of $\beta$-carotene in two Dunaliella species, Plant Cell Physiology, 43, 877884.

- Young E., Beardall J. and Giordano M. (2001). Inorganic carbon acquisition by Dunaliella tertiolecta (Chlorophyta) involves external carbonic anhydrase and direct $\mathrm{HCO}_{3}^{-}$utilization insensitive to the anion exchange inhibitor DIDS, European Journal of Phycology, 36, 81-88.

- Young E.B. and Beardall J. (2005), Modulation of photosynthesis and inorganic carbon acquisition in a marine microalga by nitrogen, iron and light availability, Canadian Journal of Botany, 83, 917-928.

- Xu Q.X. (1994), Studies on microalgae from Antarctic Hypersaline Lakes. PhD thesis, Monash University, 252 pp.

- Zenvirth D. and Kaplan A. (1981) Uptake and efflux of inorganic carbon in Dunaliella salina, Planta 152, 8-12. 